AUTOR:

António Marques ${ }^{1}$

${ }^{1}$ Faculdade de Desporto, Universidade do Porto, Portugal

https://doi.org/10.5628/rpcd.21.S1.30

\section{A Universidade e os desafios da formação pós-graduada}

Intervenção como orador principal no dia da FADEUP 3 de Dezembro de 2018 procura de melhores oportunidades de emprego, mas também o esforço coordenado dos governos de muitos países de criação de forças de trabalho altamente competentes. Com efeito, a especulação sobre as razões pelas quais a educação pós-graduada se tornou um tema central na agenda dos governos e das universidades apoia-se na crença de que a economia do conhecimento do Séc. XXI requer trabalhadores com conhecimentos avançados, capazes de resolver problemas complexos usando competências intelectuais e analíticas sofisticadas. Uma economia com postos de trabalho de um tipo novo que exigirão tarefas menos rotineiras, mais complexas e, também, mais exigentes.

$\mathrm{Na}$ Europa, o Processo de Bolonha - com a estruturação das formações universitárias em três ciclos de ensino, a redução do número de anos de formação pré-graduada, e a mudança de orientação sobre os objetivos da formação inicial - veio determinar uma procura crescente pelas formações pós-graduadas.

A expansão da formação pós-graduada trouxe, também, grandes desafios às IES: a transformação de sistemas de elite em sistemas massificados; as dificuldades de financiamento de uma formação pós-graduada em acelerado crescimento; a necessidade de equilíbrio entre o número crescente de estudantes no acesso, com expectativas de realização do seu potencial humano, e a qualidade das formações; a necessidade de assegurar a reputação dos programas de formação num mundo cada vez mais competitivo; a enorme diversidade de estudantes e de programas de pós-graduação.

Antes marcadamente elitista, a educação superior está a massificar-se e com a massificação cresceu também o número de estudantes que procuram adquirir na formação pós-graduada os conhecimentos científicos e as competências técnicas e profissionais que a formação pré-graduada não thes proporcionou. Porém, isto não se faz sem custos para os estudantes e as respectivas famílias. De facto, um número crescente de países tem vindo a passar para os estudantes uma parte substancial dos custos de formação, obrigando muitos estudantes a trabalhar para suportar estes custos e, como consequência, resultando num aumento da duração dos cursos e das taxas de abandono e na diminuição da qualidade.

2. Tradicionalmente, a formação pós-graduada era essencialmente académica e tinha como objetivo promover o desenvolvimento de uma investigação original numa área de estudos. No presente é, também, orientada para o desenvolvimento de conhecimentos e competências para o exercício de uma profissão específica.

Esta questão marcou o debate em muitos países, onde, até há pouco tempo, largos sectores das universidades se opunham a uma pós-graduação profissionalizante. Hoje, sectores profissionais em alguns dos países mais desenvolvidos do mundo estão a estabelecer critérios para o recrutamento de recursos humanos já ao nível de doutor e a colaborar com as universidades em programas de capacitação de pós-graduados que incluem o estágio em empresas.
1. Num tempo de extraordinárias mudanças económicas e demográficas, a educação sude um significado muito diferente do que tinha meio século antes. Na origem agricultura para uma sociedade industrial e, mais contemporaneamente, para uma econoabrir novas possibilidades de desenvolvimento nas sociedades, uma classe média crescente está a criar uma demanda sem precedentes no acesso à educação superior, e os modeser postos em causa.

Também as economias emergentes, em desenvolvimento, têm vindo a colocar a educasuperior e numa mobilidade acrescida de estudantes internacionais.

Resultados de alguns estudos têm mostrado que quanto maior é o número de estudantes que atingem qualificações superiores, maior é a procura por níveis de educação mais avançados. De facto, subjacente ao crescimento do número de estudantes de pós-graduação está a massificação do ensino superior, a qual tem possibilitado a uma população cada vez mais vasta uma educação que vai além do primeiro ciclo de ensino. À medida que o mundo se torna mais competitivo e as economias mais integradas, há evidência de que o primeiro grau de formação já não é suficiente e se faz necessário investir em qualificações mais elevadas. Esta tendência já não traduz, apenas, a vontade de cada indivíduo de 
A própria organização dos cursos denuncia preocupação com a resposta aos desafios das sociedades. Conscientes de que a fertilização cruzada entre as disciplinas alimenta o pensamento no mundo contemporâneo e deve, por isso, aparecer refletida na educação doutoral, um cada vez maior número de países valoriza a investigação interdisciplinar em programas doutorais que transcendem as fronteiras disciplinares e integram estudantes com diferentes backgrounds científicos. Esta concentração de recursos em programas de doutoramento transversais (resultantes de processos de reorganização de pequenos programas de doutoramento de perfil disciplinar) pretende promover a criação de diversidade e massa críticas na educação doutoral e oferecer aos estudantes a possibilidade de alargar os seus horizontes científicos.

Nos últimos 10-15 anos as IES investiram esforços e recursos consideráveis na melhoria dos ambientes da investigação doutoral: criando escolas doutorais ou de pós-graduação; introduzindo disciplinas e programas de seminários como parte da formação doutoral; oferecendo aos estudantes a oportunidade de discutir os seus projetos com outros estudantes de investigação; e fazendo um grande investimento financeiro para a formação de competências profissionais.

De facto, também o doutoramento - antes uma qualificação para uma carreira académica - é hoje entendido pelas universidades e entidades empregadoras como uma qualificação de alto nível que prepara as pessoas para pensar de uma forma profunda e rigorosa acerca de um assunto e traduzir este conhecimento em novas oportunidades para a sociedade.

3. Pode a pós-graduação ser massificada sem pôr em causa a qualidade? Não devem os cursos de pós-graduação, pela sua própria natureza, implicar uma rigorosa seleção que se apoie em requisitos de admissão, tanto mais exigentes quanto mais alto é o padrão da universidade? Estarão todos os estudantes que concluem a sua formação inicial (independentemente do seu interesse) preparados para uma especialização aprofundada e uma formação científica avançada?

Há especialistas que pensam ser próprio dos sistemas em expansão que o alargamento do ensino superior resulte numa diminuição da qualidade da educação. Por um lado, porque 0 alargamento do universo na procura se faz acompanhar por uma diminuição dos níveis de preparação dos candidatos ao ensino superior; e, por outro lado, porque com a expansão é mais difícil reunir os recursos docentes em quantidade suficiente para assegurar essa qualidade.

Mas, há também quem pense que o forte crescimento do número dos estudantes de mestrado levanta sérias preocupações com a qualidade e com o potencial impacto que sua diminuição pode ter nos programas doutorais e na própria preparação para o mundo do trabalho. Neste sentido, a LERU (League of European Research Universities) defende que os programas de pós-graduação devem ser mais do que, apenas, treinar pessoas para ir para o mundo do trabalho, e que é o talento, mais do que a tecnologia, o que a sociedade e as empresas necessitam das universidades.
Com a pressão da globalização, a forte competição nacional e internacional, e a crescente mobilidade de estudantes, não é surpresa que um número crescente de países dedique uma particular atenção às questões da qualidade. Isto tem vindo a ser feito através: (i) da adopção de instrumentos institucionais que garantam a qualidade académica; (ii) da criação de quadros de referência para as qualificações; (iii) da definição de padrões de qualificação dos estudantes no acesso; (iv) de um acompanhamento mais cuidado dos percursos dos estudantes durante as formações pós-graduadas; e (v) de uma forte aposta na internacionalização dos programas.

Em muitas IES, os programas de investigação pós-graduada têm vindo a instituir um "Código de Prática", o qual integra um conjunto de documentos e instrumentos que procura garantir a qualidade académica e as orientações definidas para as IES pela Agência para a Garantia de Qualidade no Ensino Superior. Este Código assume que cada IES deve dispor de sistemas próprios que permitam, através de uma verificação independente, avaliar a qualidade, as orientações e princípios que promove, e a efetividade dos seus sistemas de garantia de qualidade. Este Código integra por isso secções estruturadas numa série de preceitos, princípios e explicações que a comunidade universitária identificou como impor tantes para a garantia da qualidade e dos padrões académicos. Cada IES deve ser capaz de demonstrar que os aspectos que decorrem dos preceitos estão a ser resolvidos por elas, através dos seus processos organizativos e de gestão. E, por isso, o Código resulta numa afirmação de boas práticas que foram endossadas às IES pela comunidade universitária.

4. Uma preocupação comum centra-se nos padrões de qualificação dos estudantes à entrada, por forma a evitar que a expansão dos números no acesso prejudique a qualidade dos que entram nas formações pós-graduadas. Um cada vez maior número de países utiliza procedimentos de avaliação dos candidatos às pós-graduações em ciência como um modo de assegurar que estes estudantes dispõem do potencial para serem bem sucedidos. Muitos países procuram, também, assegurar que os candidatos aos programas de pós-graduação têm boas competências linguísticas, e que todos aqueles que têm as capacidades e qualidades para obter sucesso, mas não têm disponibilidades financeiras para custear as suas formações, não sejam condicionados no acesso. Porém a remoção de barreiras representadas pelos constrangimentos financeiros tem sido lenta.

A monitorização do progresso dos estudantes durante a formação pós-graduada é também uma preocupação. 0 que é que as IES estão a fazer, não apenas para atrair os melhores estudantes, mas também para corresponder às suas expectativas de formação? Que estratégias estão as escolas de pós-graduação a desenvolver para melhorar a experiência e a qualidade das realizações dos estudantes durante os anos da sua formação?

Estas são questões para as quais procuram respostas muitas universidades, promovendo iniciativas inovadoras, criando ambientes favoráveis de trabalho, e encorajando os professores a ouvir os seus estudantes e a dar-lhes a ajuda de que eles precisam nas diferen- 
tes fases da sua pós-graduação e nas suas futuras carreiras. Por exemplo: (i) apoiando-os na aquisição e aperfeiçoamento de competências linguísticas; (ii) organizando cursos de curta duração orientados para as respostas aos problemas dos estudantes - como escrever um artigo científico, como decorre o processo de publicação científica, como utilizar as suas competências em atividades de consultoria...; (iii) oferecendo programas com blended learning e virtual learning, procurando ajustar a formação, de forma flexível, às conveniências dos estudantes; (iv) recrutando académicos experientes como mentores dos estudantes; (v) melhorando a formação dos supervisores; (vi) oferecendo aos estudantes ambientes de trabalho estimulantes e oportunidades de participação em redes científicas.

Estes dois últimos aspectos - a formação dos supervisores e a participação dos estudantes em redes científicas - são considerados cruciais por muitos especialistas. A qualidade do trabalho de supervisão e o próprio acesso à supervisão não são considerados satisfatórios por muitos estudantes de pós-graduação. Esforços para melhorar a formação de supervisores estão, por isso, no centro das preocupações de muitas universidades. No que se refere às redes colaborativas, uma vez que expõem os estudantes a contatos com especialistas internacionais e a uma potencial interação com um vasto número de investigadores, essas redes criam ambientes de investigação muito estimulantes que asseguram condições de grande sucesso na educação pós-graduada. Este aspecto é particularmente relevante na educação doutoral, que deve estar embebida num forte ambiente e cultura de investigação científica para assegurar que as oportunidades de fertilização cruzada entre disciplinas possam promover a necessária interdisciplinaridade. Por esta razão, acredita-se que a educação doutoral é melhor desenvolvida em instituições de investigação intensiva ou integrada em parcerias, onde os benefícios de um largo espectro de atividades de investigação possam ser explorados. Complementarmente, muitas universidades estão ainda a oferecer aos graduados competências pessoais e profissionais na área da gestão, como parte da sua experiência doutoral.

5. A capacidade de olhar mais longe esteve na origem do desenvolvimento das civilizações. Foram a miopia cultural, o medo do estrangeiro e a endogamia que as levaram à destruição. Por isso, como nota Gonçalves (2009) a vocação cosmopolita, intercultural e internacionalista das universidades não é uma opção, mas uma necessidade.

Quase todos os governos do mundo estão a fazer esforços para internacionalizar os seus sistemas de ensino superior, esperando que do processo de internacionalização e da colaboração com outras IES resultem programas mais fortes e um avanço na qualidade das formações. Procuram, desta forma, promover sinergias entre as instituições e alimentar relações pessoais que são cruciais para o sucesso de longo prazo numa economia global cada vez mais aberta.
Nos últimos anos, um elevado número de IES está já a operar internacionalmente num processo que envolve a criação de parcerias entre instituições e inclui a criação de programas pós-graduados conjuntos ou em associação. Estes esforços têm sido limitados em muitos países por obstáculos associados ao enquadramento jurídico da colaboração internacional na criação de programas pós-graduados. As universidades que vão mais à frente são aquelas que estão a encontrar soluções mais rápidas para os problemas, superando os constrangimentos de ordem jurídica e normativa que as próprias legislações nacionais estabelecem à criação de graus conjuntos ou ao reconhecimento de graus em colaboração internacional.

Uma economia global baseada no conhecimento, vai também forçar uma maior atenção à "internacionalização do curriculum", uma vez que o conhecimento e as competências de todos os graduados têm de refletir que eles estão aptos a operar num mundo e num mercado de trabalho cada vez mais aberto. De facto, numa economia global, não faz sentido orientar as qualificações dos estudantes apenas para as necessidades dos mercados de trabalho locais. E se as universidades devem preparar os estudantes para as necessidades dos mercados internacionais, também os currículos necessitam de ser internacionalizados.

6. Uma cada vez maior e melhor integração entre as formações de mestrado, de doutoramento e de pós-doutoramento corresponde, também, a uma orientação com grande acolhimento internacional.

Os postdocs tornaram-se elementos chave da força de trabalho universitária, a sua parte mais barata e um meio disponível para aumentar a produtividade académica. 0 seu número está a crescer rapidamente, prevendo-se que, dentro de uma década, possa exista mais de 1 milhão em todo mundo, em resultado do cada vez maior número de graduados com doutoramento.

primeiro Forum Humboldt sobre as perspectivas de carreira pós-doutoral, realizado em Washington em 2007, constatou que: os indivíduos com muito talento têm agora uma elevada mobilidade; os países estão a implementar de forma crescente medidas políticas para atrair investigadores estrangeiros e expatriados e a concentrar o seu investimento em potencial para a investigação (talento + instalações e equipamento + redes); há um aumento nos fluxos de retorno aos países de origem dos investigadores treinados no estrangeiro; as assimetrias de poder entre os países podem desequilibrar (em favor dos países com mais poder) a mobilidade dos talentos; centenas de companhias que operam a nível global estão a oferecer posições de postdoc em laboratórios bem equipados, com condições atrativas e boas perspectivas de carreira, competindo diretamente com as universidades no mercado dos talentos; a mobilidade não substitui o desenvolvimento da capacidade de investigação a um nível local ou nacional. 
7. A sociedade está a mudar de uma forma muito célere e estão a aumentar as incertezas e os desafios que acompanham os períodos de mudança.

Também as universidades estão a mudar. Saíram das torres de marfim, num processo de aprendizagem não isento de dúvidas, de hesitações e de riscos, e acrescentaram às suas missões tradicionais - o ensino e a investigação - uma terceira missão - a abertura à sociedade. E têm-no feito num quadro de convulsão interna mais ou menos acentuado, onde coexistem posições conservadoras, reativas à mudança, e posições mais favoráveis às dinâmicas de progresso.

A massificação do ensino superior é uma consequência dessas mudanças. Com o aumento do número de candidatos à formação pré-graduada, aumentou também o número de estudantes que procuram aceder a níveis mais avançados de educação superior na sociedade do conhecimento.

E se a massificação do ensino superior tem vindo a pressionar fortemente a qualidade das formações pós-graduadas oferecidas pelas universidades, é também cada vez mais claro que na sociedade global em que vivemos a competição irá acentuar-se. E que, no futuro, dificilmente haverá lugar para instituições sem qualidade. Por isso, seja a oferta pós-graduada orientada para a ciência ou para o ensino, para a academia ou para o mundo de trabalho, os estudantes que estão a ser chamados a pagar a sua formação vão querer escolher, cada vez mais, instituições de formação onde a excelência esteja no centro das preocupações das IES, seja na investigação científica, seja na formação pós-graduada.
AUTOR:

Eckhard Meinberg ${ }^{1}$

Deutsche Sporthochschule Köln (Universidede Alemã Colónia, Alemanh

https://doi.org/10.5628/rpcd.21.S1.37
Scientific ethics.

\section{Some fundamental remarks}

about necessities

and possibilities

\section{INTRODUCTION}

Whenever one tries to connect Science and Ethics, it is necessary to look into the past to get a better understanding of the current situation. That is why I would like to start this article by talking about important, pre-modern roots.

The next part will deal with the necessity of a modern scientific ethics. The goal of this article, which also makes up the main part of these considerations, will be about giving an outline as well as illustrating basic problems of the new area of scientific ethics as a scientific sub-field. At last, I will suggest a very contemporary challenge.

\section{BACK TO THE ROOTS}

You can start the explanation of this topic by studying those ancient sources which are linked to the Greek philosophical "heroes", Plato and Aristotle. I will, however, concentrate on Aristotle. "Why is this?", you may ask. His pioneer works had a stronger influence on modern philosophy, science and ethics than those of his teacher Plato, whom he criticised several times. Aristotle's Metaphysics is a masterpiece of science. Already the opening sentence is of fundamental relevance: „Mankind asks for knowledge by nature“ (translation by E.M.) is an undeniable, anthropological fact. A special kind of knowledge, in fact its highest and purest form, is the scientific one. Aristotle's Metaphysics has founded the 